\title{
Influence of Light Spectra on the Production of Cannabinoids
}

\author{
Pascal Amrein ${ }^{\mathrm{a}}$ Stefan Rinner $^{\mathrm{a}}$ Tindaro Pittorino $^{\mathrm{a}} \quad$ Joan Espel ${ }^{\mathrm{b}}$ \\ David Schmidmayr ${ }^{c}$ \\ ${ }^{a}$ NTB Interstate University of Applied Science, Buchs, Switzerland; b Ai Fame GmbH, Neckertal, Switzerland; \\ cSANlight Research GmbH, Bludenz, Austria
}

\section{Keywords}

LED $\cdot$ Light spectrum $\cdot$ Cannabinoid content $\cdot$ Indoor growth Photosynthetic photon flux density

\begin{abstract}
In recent years, more attention has been paid to cannabis from both medical and political points of view. This study investigates the influence of 5 different light spectra on the active substance content in THC-poor hemp of the Alessia chemotype II variety. The focus is on comparing conventional growing under metal halide lamps with growing under high-pressure sodium (HPS) vapor lamps with regard to different spectra of LED lighting modules. Growing was carried out in 10 growing boxes under controlled and mostly identical conditions for all boxes. The photoperiod during the vegetative phase was $18 \mathrm{~h}$ light and photosynthetic photon flux density $\sim 520 \mu \mathrm{mol} \cdot \mathrm{m}^{-2} \mathrm{~s}^{-1}$. The flowering phase was $12 \mathrm{~h}$ light and $\sim 540 \mu \mathrm{mol} \cdot \mathrm{m}^{-2} \mathrm{~s}^{-1}$. During the experiment, $\mathrm{CO}_{2}$, temperature, and humidity were measured and logged. Additionally, weekly measurements of chlorophyll, electric conductivity of the fertilizer, activity measurement (salt content) of the soil, and pH value of the soil were checked. The content of cannabinoids was measured by
\end{abstract}

(C) 2020 The Author(s)

Published by S. Karger AG, Basel

This article is licensed under the Creative Commons AttributionNonCommercial-NoDerivatives 4.0 International License (CC BY NC-ND) (http://www.karger.com/Services/OpenAccessLicense). Usage and distribution for commercial purposes as well as any distribution of modified material requires written permission. high-performance liquid chromatography (HPLC). Plant height and growth were monitored during the whole experiment by cameras taking pictures every $30 \mathrm{~min}$ and loading them onto a cloud storage platform. Cannabinoid content was measured using HPLC. Plant wet weight was determined at the end of the experiment and showed that plants under the high pressure lamp treatment had less flower weight than those under the LED treatment. In conclusion, it could be shown that certain LED spectra can considerably increase the amount of cannabinoids with respect to conventional illumination (HPS).

(c) 2020 The Author(s) Published by S. Karger AG, Basel

\section{Introduction}

The reaction of plants to light strongly depends on the amount and ratio of different wavelengths in the illumination spectrum. Unlike the cultivation of most other plants, cultivating cannabis is not primarily focused on the crop yield, size, and/or weight but on the content of several chemical compounds, such as specific cannabinoids and terpenes. 
Growing plants indoors has the great advantage of having better control of various ambient conditions, such as $\mathrm{CO}_{2}$, humidity, or temperature. With the right environment, the plants can grow with less stress and produce more flowers. Moreover, 4-6 harvests per year become possible.

One significant negative factor is the high energy consumption in darkrooms. One percent of the energy consumption in the USA is used for cannabis cultivation. The average cultivator needs $37 \%$ of the energy just for conventional lighting (metal halide lamps [MHLs] and high-pressure sodium [HPS] lamps). For average US conditions, producing $1 \mathrm{~kg}$ of processed cannabis results in 4,600 kg of $\mathrm{CO}_{2}$ emissions to the atmosphere (and 50\% more when off-grid diesel power generation is used) [1].

Concerning the growing area, photosynthetic photon flux density (PPFD) is an important parameter with respect to yield. The PPFD value depends on distance, radiation characteristics, and light source. For accounting purposes, it is better to compare cost/PPFD rather than cost/Watt since solid-state lighting with LEDs will use less energy for the same number of photons [2].

Already in 1883 Engelmann was able to demonstrate experimentally which algal segments were releasing the most $\mathrm{O}_{2}$ and thus photosynthesizing the most using aerobic bacteria. Light in the violet-blue and red portions of the spectrum is most effective in driving photosynthesis [3].

Additional experiments showed the process of photosynthesis. Photosynthesis is the only process in nature to generate chemical energy from light. Chloroplasts, as the key organelles for this reaction, work in 2 steps. The first step is photosystem II, which needs a wavelength peak of $\sim 680 \mathrm{~nm}$, and the second step is photosystem I, which needs a wavelength peak of around $700 \mathrm{~nm}$ [4]. Furthermore, it could be shown that mixing 680 and 700 $\mathrm{nm}$ wavelengths is more effective than just 1 (Emerson effect) [5].

A recent study from 2018 showed an increase of the cannabinoids cannabidiol (CBD) and THC in the flowers with LEDs. The PPFD for all setups was $\sim 450$ $\mu \mathrm{mol} \cdot \mathrm{m}^{-2} \mathrm{~s}^{-1}[6]$.

Nowadays, LED technology allows for specific illumination spectra and higher lighting efficiency. The physical limit is $683 \mathrm{~lm} / \mathrm{W} @ 555 \mathrm{~nm}$. For white light, it is about $350 \mathrm{~lm} / \mathrm{W}$. Also, the PPFD/W of LED technology depends on the ballast, optics, and wavelength. LEDs are more robust and have a longer lifetime than conventional lights.
To date, $90 \%$ of Canadian cultivators are HPS cultivators, since they are proven and are cheaper to purchase. The development of LEDs is fast and prices are decreasing [7]. This study investigates the impact of various light spectra with respect to the yield of cannabinoids.

\section{Materials and Methods}

In order to examine the impact of the spectral composition of illuminating light, 10 growing boxes were equipped with several light sources ( 2 HPS lamps and 4 different LED light spectra in 2 boxes each).

Unrooted C. sativa L. cuttings from multiple motherplants of "Alessia" chemotype II (Ai Fame, Schönengrund, Switzerland) were dipped into root hormone powder (indole-3-butyric acid), inserted into easy plugs CT104C (Eazy Plug in DS Goirle, the Netherlands), and watered. The cuttings were kept in a greenhouse $(57 \times 38 \times 22 \mathrm{~cm})$ in $90 \%$ relative humidity at $\sim 25^{\circ} \mathrm{C}\left( \pm 2^{\circ} \mathrm{C}\right)$ and were lit for $18 \mathrm{~h}$ (16:00 until 10:00) per day by 2 LED lights (Philips CoreLine Batten $4,000 \mathrm{~K}$ ) with $\sim 195 \mu \mathrm{mol} \cdot \mathrm{m}^{-2} \mathrm{~s}^{-1}$. After 12 days, all the cuttings had taken root, and the greenhouse windows were opened for acclimatization. After 14 days in the greenhouse, the best rooted cuttings were transplanted into 1-L trays with earth substrate 144 from Ricoter (Aarberg, Switzerland) and placed in the growing boxes $(115 \times 65 \times 115 \mathrm{~cm})$. After 3 days in the growing chambers, they were fertilized for the first time.

Ten plants were placed in each of the 10 boxes. Each box was equipped with a Dosatron Compact D07RE125 and a Raspberry Pi 3 (RPI) for measurement. The vegetation fertilizer was "Plantaaktiv $18+12+18$ Type A" (Hauert, Grossaffoltern, Switzerland) with an electric conductivity between 1 and $1.2 \mathrm{mS} / \mathrm{cm}$ and for the flowering, "Plantaaktiv $10+20+30$ Type B" (Hauert, Grossaffoltern, Switzerland) with an electric conductivity between 1.3 and $1.5 \mathrm{mS} /$ $\mathrm{cm}$ without $\mathrm{pH}$ correction. The multifunctional device "COMBI 5000" (STEP Systems, Nuremberg, Germany) measured activity measurement and $\mathrm{pH}$ directly in the soil. The activity measurement value was between 0.25 and $0.5 \mathrm{~g} / \mathrm{L}$ for all the plants during the test, which is a good value for cannabis. The $\mathrm{pH}$ was $\sim 5( \pm 1)$, with recommended $\mathrm{pH}$ values being in the range of 5.8-6.5 with soil.

The MHL "Philips MASTER HPI-T Plus $400 \mathrm{~W}-4,500 \mathrm{~K}$ ” used as the standard lighting for the Ai Fame in the vegetation phase operated with $400 \mathrm{~W}$ was used for the flowering phase for $18 \mathrm{~h}$ (16:00 until 10:00) and the sodium vapor lamp "Sylvania SHP-TS GroLux $400 \mathrm{~W}-2,050 \mathrm{~K}$ ” operated with $275 \mathrm{~W}$ for $12 \mathrm{~h}$ (22:00 until 10:00). The ballast was the Gavita DigiStar $400 \mathrm{~W}$ dimmable.

The LED light source was the model Q6W (SANlight, Bludenz, Austria) with different LED chips from Osram. All are dimmable and had a maximum consumption of 215 W/230 V AC (see Fig. 1). As mentioned above, 4 different spectra were used in the experiment.

For the flowering phase, the PPFD measurements took place inside the closed growing box with the plants present. The measurement was carried out in the middle of the box at a distance of $52 \mathrm{~cm}$ for the LED and $48 \mathrm{~cm}$ for the HPS from the light source (47 $\pm 1 \mathrm{~cm}$ from the bottom of the box). For the vegetation phase, a PPFD value of $\sim 520 \mu \mathrm{mol} \cdot \mathrm{m}^{-2} \mathrm{~s}^{-1}$ was measured by the MHL as reference for the LEDs (without plants in the box). After 22 days, the plants were transplanted into 2 -L pots, and the PPFD measure- 


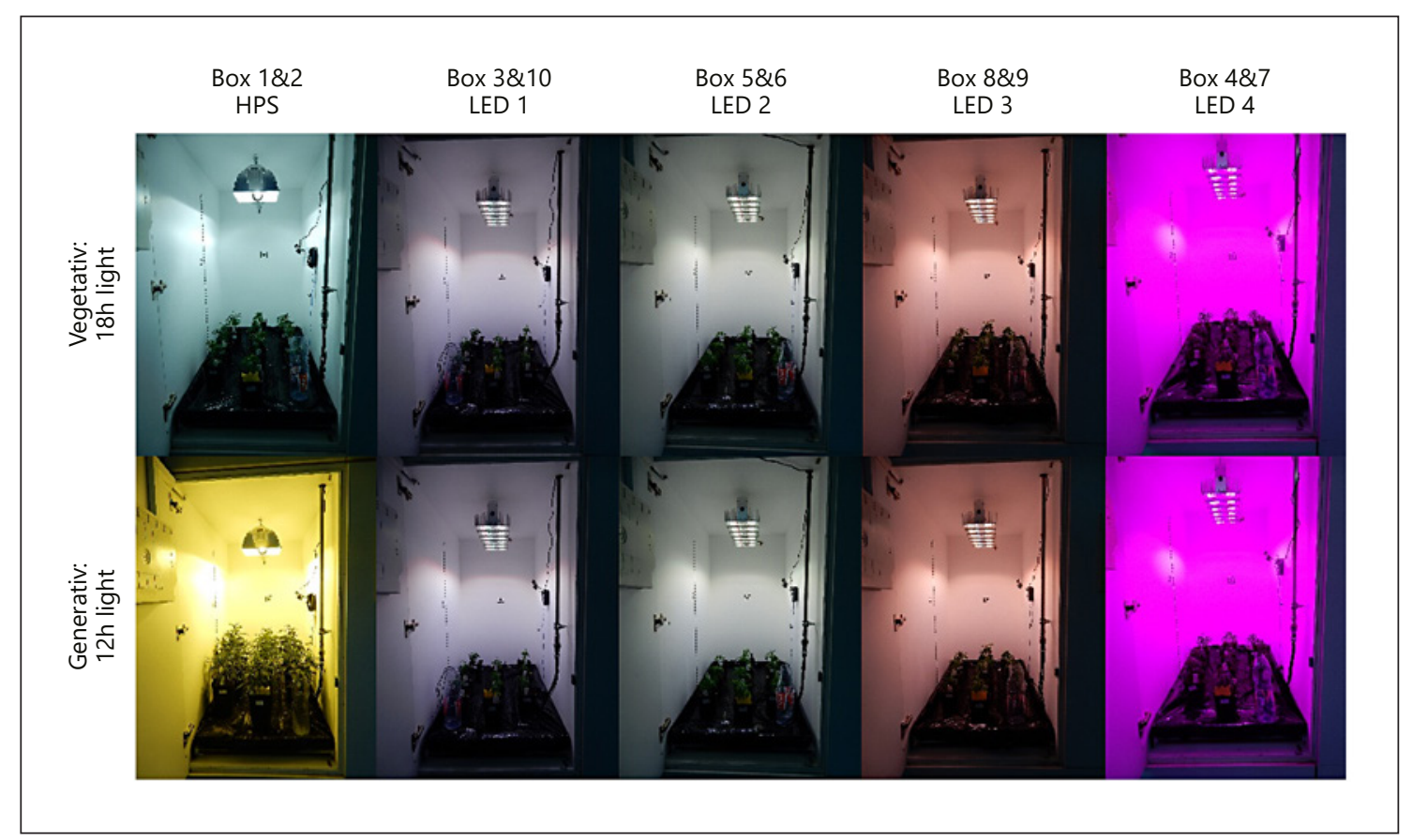

Fig. 1. Box setup. HPS, high-pressure sodium.

ment of the HPS showed $\sim 540 \mu \mathrm{mol} \cdot \mathrm{m}^{-2} \mathrm{~s}^{-1}$ (with plants present in the box). The PPFD values were set after measurement by the LEDs.

The RPI was connected with a $\mathrm{CO}_{2}$, temperature, and humidity sensor "SCD30" (Sensirion, Steaffa ZH, Switzerland) at pot height (11 cm from bottom) and a pressure, temperature, and humidity sensor "BME280" (Bosch, Gerlingen, Germany) at flower height ( $45 \mathrm{~cm}$ from bottom). The sensors took measurements every 30 s. Five different spectra were tested (see Fig. 2, 3). Two boxes had the same light spectrum. Additionally, the boxes with the same spectrum were monitored using 2 different types of camera. One box had the camera "Raspberry Pi Modul V2" and the other had the camera "Raspberry Pi NoIR V2" on the RPI (without IR filter) for motion detection and for capturing pictures every $30 \mathrm{~min}$ for documentation. The climate was temperature controlled by 1 exhaust fan and 1 inlet fan for all boxes. The temperature during the test was mostly at $25^{\circ} \mathrm{C}\left( \pm 5^{\circ} \mathrm{C}\right)$. Humidity was $50 \% \mathrm{Rh}$ $( \pm 30 \% \mathrm{Rh})$. The $\mathrm{CO}_{2}$ level was mostly in the range between 400 and $800 \mathrm{ppm}$ during the test (see further details online: https://my. pcloud.com/publink/show? code=kZMP6CkZv6CG1q4SJp4oaLp 8vfXhmX5l3wE7).

The weekly height measurements were carried out with a meter rule from the pot rim. The measurements for chlorophyll were done with a SPAD205 (Konica Minolta, Tokyo, Japan), whereas the measurements for the spectrogram and PPFD were done with a MSC15 (Gigahertz Optik). Also, measurements were done with the Raman spectrometer Mira M3 (Metrohm, Herisau, Switzerland) for the detection of the cannabinoid level.

During the last 2 weeks of the experiment, the hyperspectral camera "MV1-D2048 × 1088-HS03-96-G2" (Photonfocus, Lachen SZ, Switzerland) with a bandwidth between 460 and $630 \mathrm{~nm}$ was

Light and Cannabinoids used. During 2-3 days, each spectrum was tested. Hereby, the focus was to determine using the image the existence of cannabinoids in the flowers (trichomes).

The cannabinoid content $( \pm 0.3 \%)$ of the leaves and flowers for each box was measured with the high-performance liquid chromatograph "Agilent 1100 Series" (Agilent). Here, the measuring process is divided into the following steps: for preparation, the test material was dried at $60^{\circ} \mathrm{C}$ in the oven. After that, the test material was crushed in a hammer mill. Then, $100 \pm 10 \mathrm{mg}$ of the material was weighed (XPE205-Mettler Toledo [QAK: 0100]) in a 100-mL volumetric flask. The rest of the material (more than $500 \mathrm{mg}$ ) was used for moisture measurement (HB43-S-Mettler Toledo [QAK: 0014]). The volumetric flask was filled with methanol-chloroform solution (9:1) to the $100-\mathrm{mL}$ mark. Then, it was extracted in an ultrasonic cleaning bath (Sondrex Digitec-Bandelin [QAK: 101]) for $30 \mathrm{~min}$. Finally, small vials were filled and put in the HPLC system.

Cannabinoid content was expressed as the content of the acid and neutral pieces (general formula) [8].

$\%$ of THC Total $=\%$ of THC $+(\%$ of THCA $\times 0.877)$,
$\%$ of CBD Total $=\%$ of CBD $+(\%$ of CBDA $\times 0.877)$
$\%$ of CBG Total $=\%$ of CBG $+(\%$ of CBGA $\times 0.878)$.

\section{Results}

The cannabinoid content of CBD and wet weight of the flowers showed the best results with LED lamps. Most CBD [g] was grown under spectrum 4, which had 


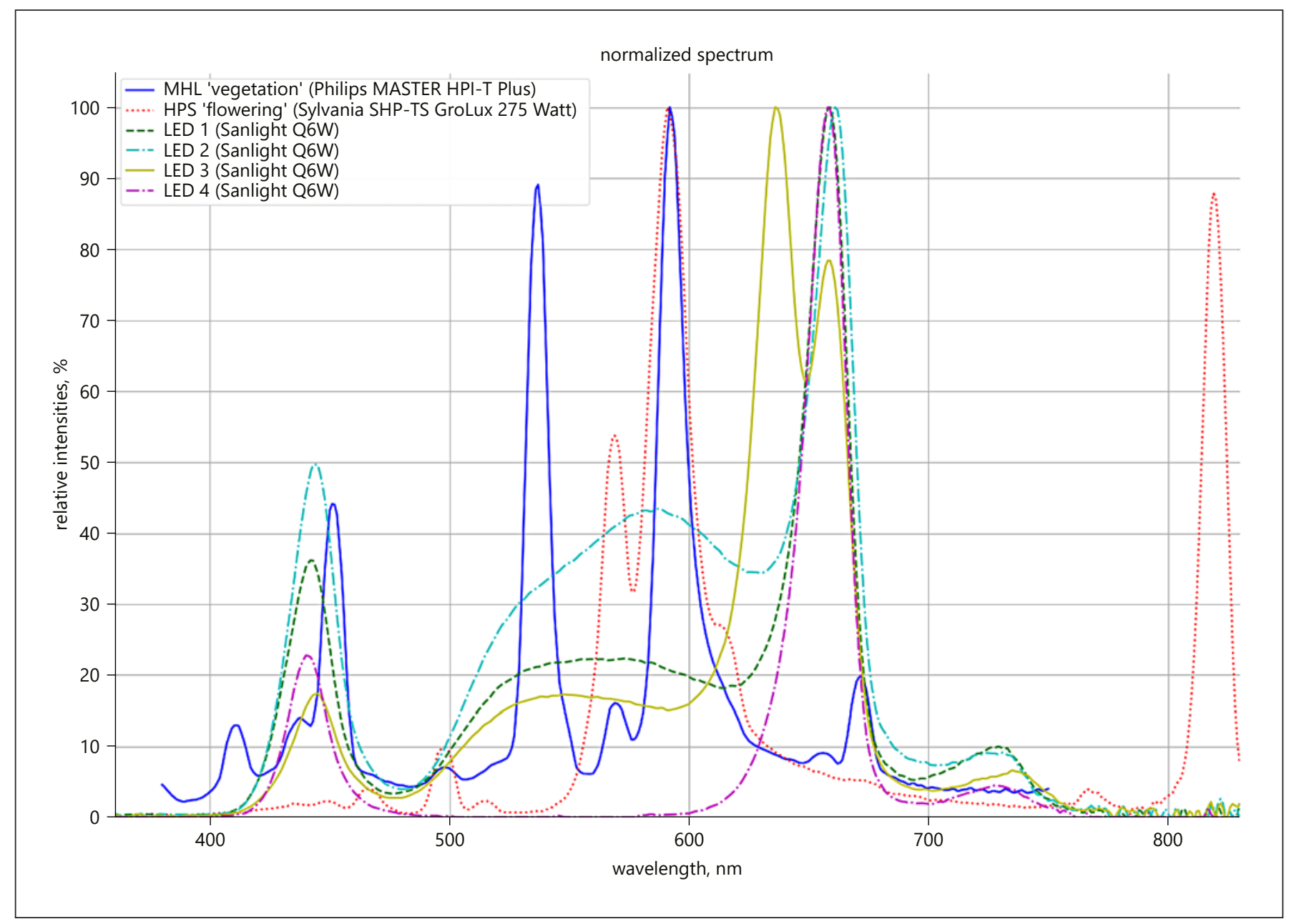

Fig. 2. Light spectrum of different light sources (measured with MSC15). MHL, metal halide lamp; HPS, highpressure sodium.

3 times more CBD than the reference boxes with HPS (see Fig. 4). Light distribution (PPFD) for the LEDs was more homogeneous than in the case of the HPS. The difference between maximum and minimum measurements of an area in the vegetation phase was for the LEDs $\pm 110 \mu \mathrm{mol} \cdot \mathrm{m}^{-2} \mathrm{~s}^{-1}$ and MHL $\pm 200 \mu \mathrm{mol} \cdot \mathrm{m}^{-2} \mathrm{~s}^{-1}$. In the flowering phase, the difference for the LEDs was $\pm 200 \mu \mathrm{mol} \cdot \mathrm{m}^{-2} \mathrm{~s}^{-1}$ and for the HPS $\pm 250 \mu \mathrm{mol} \cdot \mathrm{m}^{-2}$ $\mathrm{s}^{-1}$ (see Fig. 5, 6).

Simulation programs for simulating artificial light, for example, Relux, could show this effect in the beginning of the experiment [9]. In an industrial production environment, lights are applied at a higher distance to the plants in order to avoid heat burn on the leaves and to have a better working area. With the above-mentioned simulation program, it is possible to demonstrate the same
PPFD values due to multiple light systems with an overlapping light level even in a bigger growth area.

In contrast to an earlier study [6], this experiment could not confirm significantly higher plants with HPS lamps. The plants from each box had a height between 24 and $32 \mathrm{~cm}$ on average. In addition to that, the number of leaves from each box was approximately $25 \pm 5$ before the flowering phase. In the flowering phase, the number of leaves was stable.

The investigations using Raman spectroscopy could not demonstrate a clear correlation between peaks and CBD in comparison to pure CBD crystals (>99\%). In this case, further studies are necessary.

As a matter of fact, the use of the hyperspectral camera with a bandwidth between 460 and $630 \mathrm{~nm}$ proved unsuitable for the detection of cannabinoids. The information 


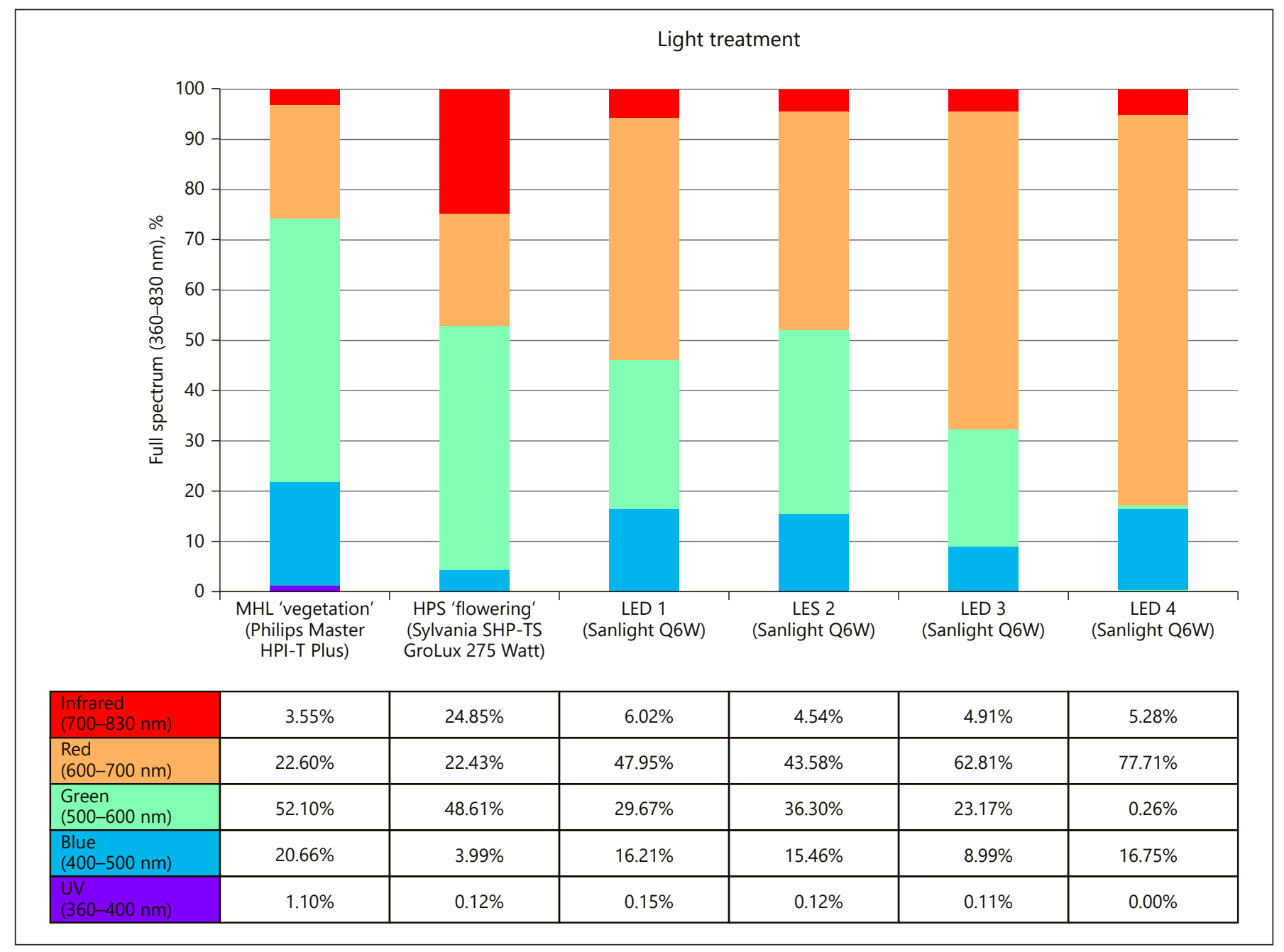

Fig. 3. Color spectrum comparison of the light sources. MHL, metal halide lamp; HPS, high-pressure sodium.

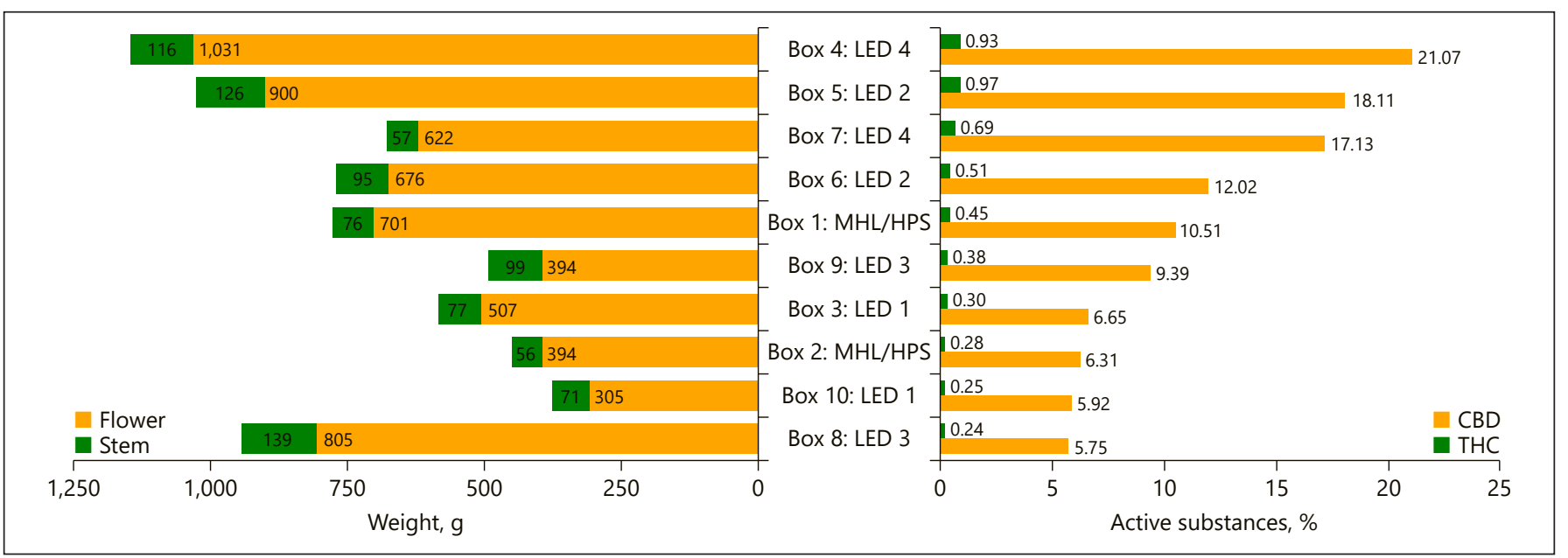

Fig. 4. Weight and cannabinoid content of the last measurement with HPLC. MHL, metal halide lamp; HPS, high-pressure sodium; HPLC, high-performance liquid chromatography; CBD, cannabidiol. 
Fig. 5. PPFD distribution of LED 4 (box 7). PPFD, photosynthetic photon flux density.

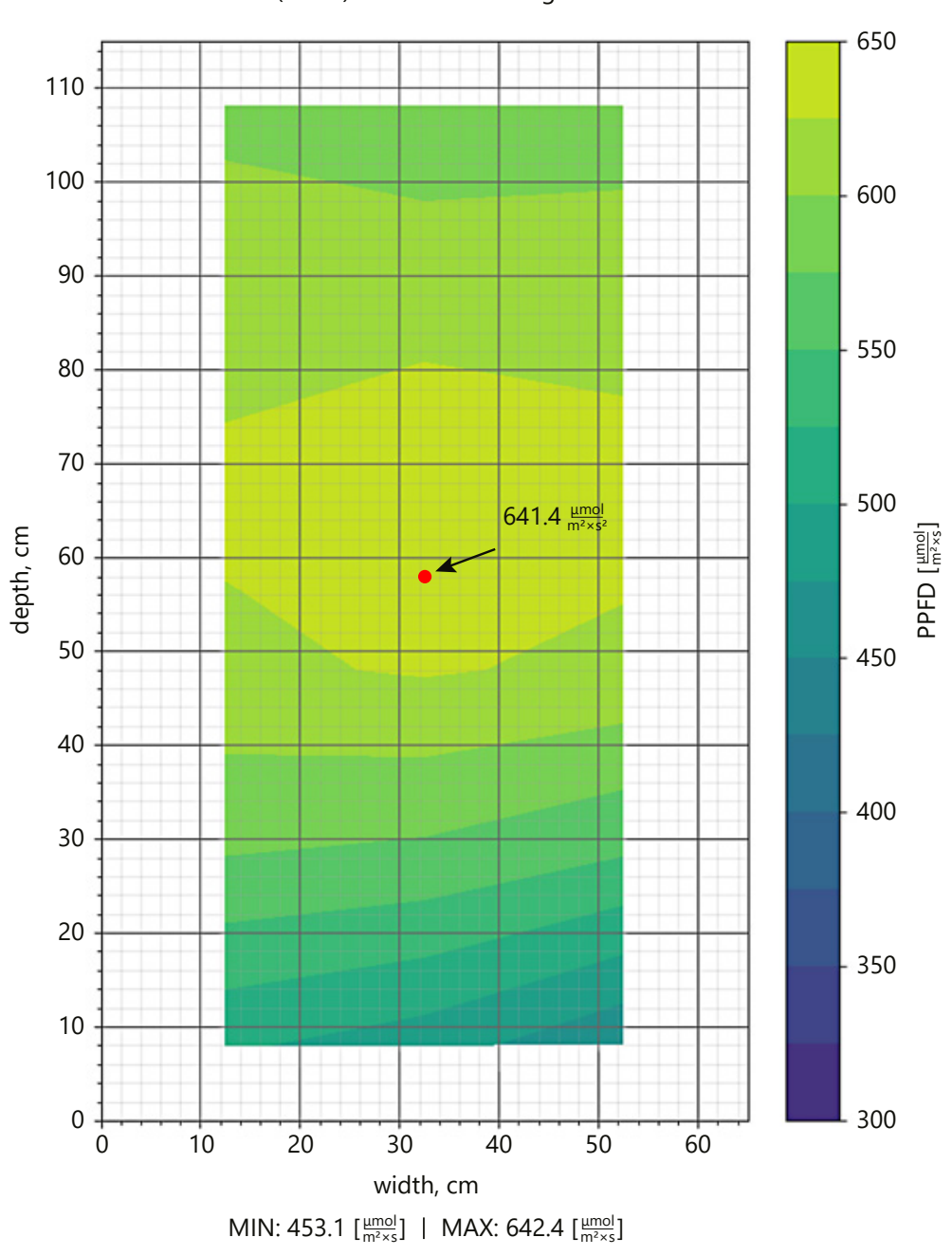

from the pictures taken using the hyperspectral camera was the same as those taken by a conventional photographic camera. Moreover, requiring wavelengths in the infrared range, the NDVI value could not be calculated. This value serves as an indicator for the health of the plant [10].

The timelapse of the plant delivered a lot of information about the plant, for example, vermin or growing status. Furthermore, the height of the plant may be monitored with a calibrated monocamera [11].

The efficiency of the LED solid-state lighting sources is increasing fast. Through the application of modular LED systems, the latest and most efficient LEDs on the market may be used with decreasing costs.

\section{Discussion/Conclusion}

The experiment has shown that the LEDs are better than HPS lamps with regard to harvest weight and active ingredient content. In accordance with earlier investigations [2], this experiment has shown that the blue/red LED spectrum achieved the best results with respect to weight and the active ingredient content CBDA. Most importantly, under spectrum 4 , which gives a pink color impression, the yield of the cannabinoid content was higher than that for all the other boxes. The plants under the "white" and "warm white" LED spectra also achieved better results in terms of weight than the plants under the 
Fig. 6. PPFD distribution of HPS (box 2). PPFD, photosynthetic photon flux density; HPS, high-pressure sodium.

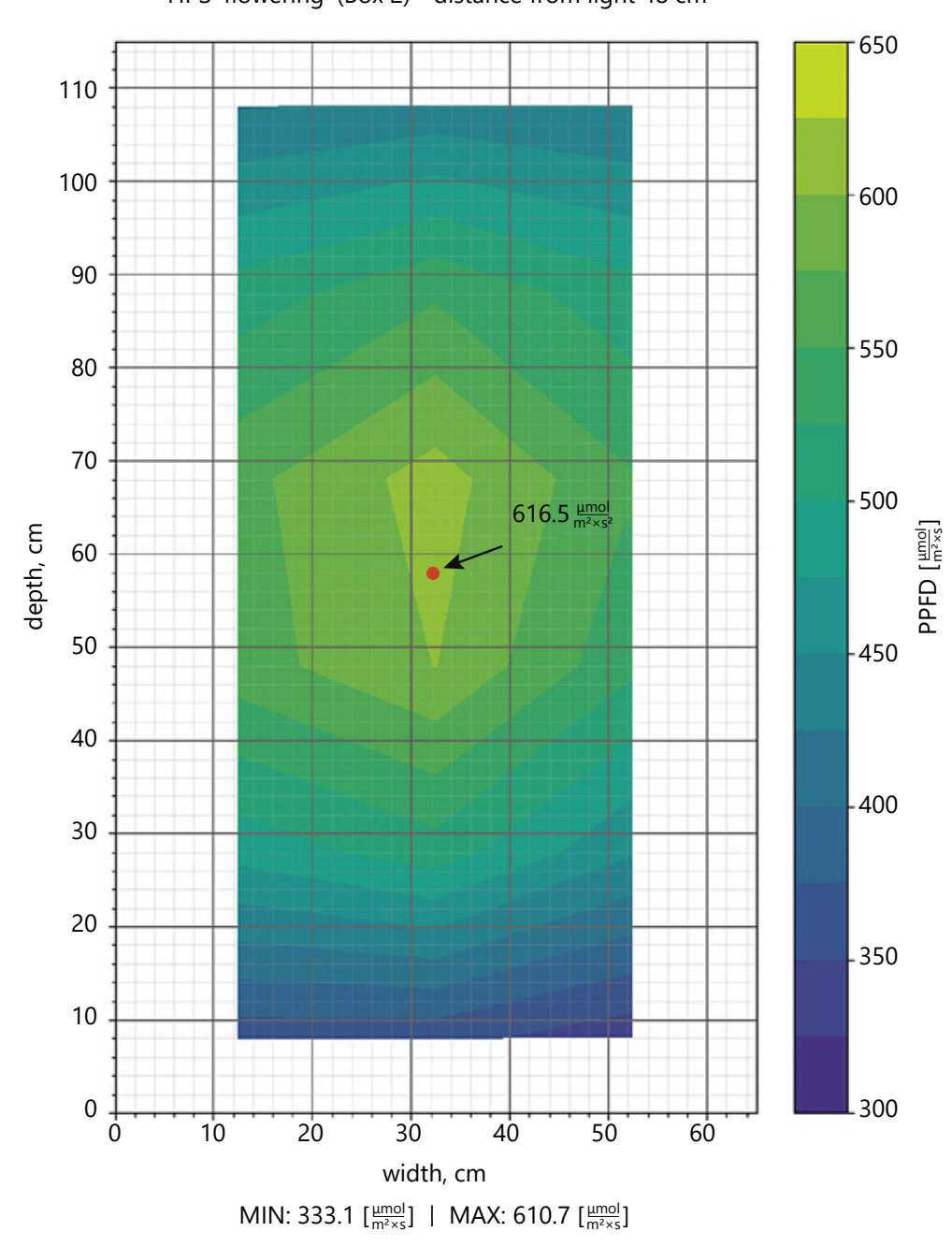

gas discharge lamps, whereas the "cold white" LEDs had the lowest yield.

During the first run of the experiment, several problems were encountered. For instance, the water supply via the dosing units was not sufficient, resulting in different fertilizer mixtures in different boxes. This problem could be solved in the last 4 weeks of flowering. Apart from that, due to a malfunction of the dosing unit, plants in box 7 were fertilized with undiluted fertilizer. This had a negative impact on the plants, and they were replaced by other plants which nonetheless still showed a rather high content of CBDA.

Light and Cannabinoids
The results could be better with a more stable Dosatron system. For this, the test needs to be repeated.

In the future, it would be interesting to test the impact of infrared lighting (Emerson effect) [5] and UV light. Also, for wake up and good night, a higher red intensity could increase the flower weight. The Raman spectrometer showed some interesting peaks but have to be tested again. The hyperspectral camera was not interesting in this case. A normal camera could see as much as this hyperspectral camera. More interesting would be the NDVI value, which needs the infrared wavelength. Because of the spectrum from the light source of the camera, this camera also would not work.

Med Cannabis Cannabinoids 2020;3:103-110 


\section{Acknowledgements}

This project work for a bachelor's thesis was carried out in cooperation with Ai Fame GmbH, SANlight GmbH, and NTB Buchs. Using the example of the hemp plant, the influence of different light spectra on the vegetative and generative growth of cannabis, and the formation of certain substances such as CBD was examined. Mr. Amrein has nothing to disclose.

\section{Statement of Ethics}

No subjects (test persons) were involved in the full experiment.

\section{Conflict of Interest Statement}

The authors have no conflicts of interest to declare.

\section{Funding Sources}

Ai Fame: Laboratory for cannabinoid analyses, growing boxes, cutting box, and interesting facts about hemp breeding. SANlight Research: $8 \times$ LED lamps (Q6W) specifically chosen by them. NTB: Raspberry Pi measurement system and human resource (test leader).

\section{Author Contributions}

Prof. Dr. Stefan Rinner (NTB Buchs): Professor of physics and photonics. Prof. Dr. Tindaro Pittorino (NTB Buchs): Professor of electronics. Joan Espel (Ai Fame): Head of laboratory at Ai Lab, Schönengrund. David Schmidmayr (SANlight): SANlight Research GmbH, Bludenz. Pascal Amrein (NTB Buchs): Bachelor student of photonics.

\section{References}

1 Mills E. The carbon footprint of indoor cannabis production. Energy Policy. 2012;46:5867.

2 Eaves J, Eaves S, Morphy C, Murray C. The profitability of growing cannabis under high intensity light. SSRN. 2019;112(2):1466-70.

3 Engelmann TW. Bacterium photometricum. Ein Beitrag zur vergleichenden Physiologie des Licht- und Farbensinnes. Arch Physiol. 1883;30:95-124.

4 Golbeck JH, Bryant DA. Photosystem I. Curr Top Bioenerg. 1991;16:83-177.

5 Govindjee R, Govindjee GH. Emerson enhancement effect in chloroplast reactions. Plant Physiol. 1964;39(1):10-4.
6 Magagnini G, Grassi G, Kotiranta S. The effect of light spectrum on the morphology and cannabinoid content of cannabis sativa L. Med Cannabis Cannabinoids. 2018;1(1):19-27.

7 CBT Staff (October 6, 2016). Types of Lighting. [cited 2019 Jan 15] Retrieved from https: //www.cannabisbusinesstimes.com/article/ types-of-lighting/.

8 Fundacion Canna (2020, 23 February): Quantification of the concentration of THC, CBD, CBG, THCA, CBDA, CBGA, THCTotal, CBDTotal and CBGTotal in HPLC. [cited 2020 Feb 23] Available from: https://www. fundacion-canna.es/en/quantification-concentration-thc.
9 Hwa-Soo L, Sook-Youn K, Jae-Hyun L. Improvement of light uniformity by lighting arrangement for standardized crop production. J Cent South Univ. 2014;21(11):4311-9.

10 El-Shikha DM, Waller P, Hunsaker D, Clarke T, Barnes E. Ground-based remote sensing for assessing water and nitrogen status of broccoli. Agric Water Manag. 2007;92(3):183-93.

11 Zhang Z. Technical report MSR-TR-98-71. A flexible new technique for camera calibration; 1998. Vol. 22.

12 Sellaro R, Crepy M, Trupkin SA, Karayekov E, Buchovsky AS, Rossi C, et al. Cryptochrome as a sensor of the blue/green ratio of natural radiation in arabidopsis. Plant Physiol. 2010; 154(1):401-9. 